\title{
TREINAMENTO EM COMUNICAÇÃO NAS EMPRESAS - FATORES A CONSIDERAR NA SELEÇÃO DE CONTEÚDOS 1
}

\author{
MIGUEL LUIZ CONTANI ${ }^{2}$ \\ DURVALI EMÍLIO FREGONEZI ${ }^{3}$
}

CONTANI, M.L.; FREGONEZI, D.E. Treinamento em comunicação nas empresas: fatores a considerar na seleção de conteúdos. Semina: Ci. Soc./Hum., Londrina, v. 15, n. 3, p. 280-284, set. 1994.

RESUMO: O presente texto é comunicação de uma série de experimentos realizados com grupos de gerentes em cursos de Especialização lato-sensu. Retrata a maneira pela qual esses profissionais vêem suas deficiências nas áreas de linguagem e comunicação, e o que revelam propriamente entender desses problemas. A dinâmica interpessoal nas organizações é focaliza $d a$, e são analisados os processos pelos quais malogram as tentativas constantes feitas pelo treinamento de habilidades de comunicaçáo. O texto é finalizado com pontos para reflexão, do interesse das áreas de Recursos Humanos, Treinamento e Desenvolvimento, docentes de cursos superiores e interessados das demais áreas.

PALAVRAS-CHAVE: Comunicação; treinamento; linguagens.

No cotidiano das organizaçöes encontra-se com frequência a frustração do objetivo não atingido. E cabe.. ria perguntar o quanto desse fenómeno se deve a incompetências no trato com a linguegem. Por outro lado, a frustração dos treinadores e responsåveis pela educação gerencial que reclamam do fato de que estão constantemente promovendo cursos de "comunicação", "relações interpessoais", "relaçōes humanas", que não modificam em nada as insuficiências levantadas e atê mesmo contribuem para um descrédito maior. Algumas reflexões são ainda necessårias.

Já se acha amplamente provado que nenhum esquema produtivo começa e termina em torno de uma única pessoa. $\dot{E}$ necessărio haver interação - processo decorrente da necessidade de divisão do trabalho. "Aqui hå um problema de comunicação"; "temos que melhorar nossas comunicações internas", e outras, são afirmaçōes que fazem parte do folclore da esmagadora maioria das organizações.

Podem-se considerar algumas competências: $A$ de efetuar bem a modalidade das comunicaçōes escritas, por exemplo. Uma empresa tem um variado número de siuações em que se solicitam relatórios escritos; outras, em que uma campanha publicitária precisa ser avaliada e aprovada; atẻ mesmo um "press-reiease" (atividade de relaçōes pủblicas) que precisa ser emitido capacidade de fazer ou avaliar as comunicaçöes feitas por outras pessoas. E o processo vai culminar na constatação de que o que se está fazendo todo o tempo é linguagem especifica e com finalidade.

As caracterizaçőes aqui apresentadas se ampliam num conjunto tão vasto de situaçōes, que se tornaria diff. cil manter uma delimitação dentro do tema. Para facilitar as primeiras abordagens, vamos ficar concentrados numa pequena parcela do processo organizacional: o desafio do administrador. Quando tem diante de si a tarefa de produzir uma comunicaçăo escrita, a tendência natural deste ưtimo ê procrastinar. Procrastinaçäo (principalmente no seu aspecto mais compuisivo) e̊ um tema que figura na maioria dos programas de educaçăo gerencial.

A compulsão a procrasínar, "Amanhã eu começo", "Amanhä eu faço". "Depois eu resolvo". $\&$ algo que encontra raizes no sentimento de ansiedade. $H a ́$, de certa forma, possibilidades jă desenvolvidas para esclarecer es" sa ansiedade, mas ainda näo hả soluçöes seguras e definitivas. Estudar comunicaçăo, no ambiente das organizaçôs - a isso esta muiro presente no treinamento $-i$ confundido com pura revisäo gramatical, Dal resultando. como autiude, uma grande indiferença, arê mesmo des" prezo. Há frustrações na história escolar de cada um quando se tratou deste estudo $\theta_{\text {, nas }}$ etapas posteriores da educação formal os cursos de graduaçăo ficaram concentrados estritamente nas materias do campo técnico abrangido.

Os atuais ditulares de importantes posições gerenciais sజ̃o unânimes om reconhecer essa falha, mas con-

1 - Trabalho apresentado no VI CELLIP - MARINGÁ - Outubro, 1992.

2 - Departamento de Letras Vernáculas e Clássicas da Universidade Estadual de Londrina, Caixa Postal 6001, Londrina, Paranå, Brasí, CEP $86051-970$.

3. Departamento de Letras Vernáculas e Clássicas da Universidade Estadual de Londrina, Caixa Posâal 600i, Londrina, Paraná, Brasîn, CEP $86051-970$. 
fessam "não terem mais a paciência" para um estudo sistemático, teórico, envolvendo linguagem, ou pelo menos, a concepção que fazem dela. Esse descrédito merece ser estudado e talvez seja um objeto potencial aguardando exame, principalmente em se considerando as condições objetivas que marcam a formação de recursos humanos no pais.

Quando se pergunta a um gerente qual a missão de seu trabalho, este imediatamente lança como resposta: gerar resultados. De fato, os compêndios de educação gerencial e os cursos básicos sobre fundamentos de gerência apontam essa como a habilidade mais central da função de gerenciar. Qualquer administrador que num dado momento não foi capaz de gerar os resultados dele esperados, não justificou sua permanência no cargo. No dicionário da Administração, a palavra resultado significa lucratividade.

Por outro lado, gerar esses resultados tem um custo humano, e são os mesmos manuais gerenciais que reconhecem que resultados não se obtêm sozinhos: mesas, cadeiras, máquinas não geram produção; há necessidade das pessoas. $O$ que o gerente tem que fazer é equacionar o mais inteligentemente possivel a relação receita/despesas, mas sua missão é obter resultados através das pessoas. E dessa forma liderança 8 o termo que pas sa a fazer parte do desafio gerencial.

Um fato bastante cotidiano surge como manifesta căo mais concreta do que vem sendo frisado: a emissão de instruçoses. Emissão e execução de instruções. É im. possivel conceber qualquer situaçäo de coordenaçäo que possa prescindir de alguma forma mesmo que rudimentar, de instrução.

Pelo fato de ser tão cotidiana, a instruçăo povoa o dia-a-dia das pessoas, a ponto de tornar-se imperceptival o fato de que todo e qualquer fluxo se mantém em mar. cha com base em instruçós. Esse fator acaba sendo re. duzido a uma simplicidade que não merece, pois, anali sadas as consequencias de eventuais tahas, revelanse como algo altamente complexo.

É complexo porque nem sempre aspectos subja. centes sâo visiveis de imediato. Passar instruçäo significa fornecer elementos de orientação. As pessoas precisam reunir um montante aceităvel dessas orientações, que thes permita pelo menos, minimamente, ter concições de executar suas tarefas ou cumprir metas $\mathrm{H}^{\mathrm{a}}$, na realidade, um enunciado que precisa ser compreendido. As carac. seristicas desse tipo de enunciado merecem maior anălise. Dar instrução năo significa necessariamente ensinar. Embora esteja presente na instrução uma grande parcela do processo ensino-aprendizagem, näo se trata unicamente de ensinar.

Hă um "tripét na comunicação escrita que simboli. za o fato de que: "para escrever bem, temos de atender a Tês funçōes b\&sicas: produzir uma resposta, tornar o pensamento comum aos outros a persuadir" (BLIKS. TEIN, 1989, p. 23). O mesmo autor ressalta ainda que se não forem atendidas primordialmente essas três funçōes, pouco adiantarå o empenho em escrever conforme a ló. gica das regras. Num capitulo intiulado Comunicar

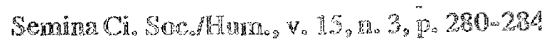

agir, Fiorin nos lembra, a propósito de ressaltar que um ato de comunicação tem sempre em vista agir no mundo: "Ao exercer seu fazer informativo [o enunciador], produz um sentido com a finalidade de influir sobre os outros. Deseja que o enunciatário creia no que the diz, faça alguma coisa, mude de comportamento ou de opinião, etc. Ao comunicar, age no sentido do fazer-fazer." (FIORIN. 1988, p. 74).

Quando o assunto é treinamento para melhoria da capacidade de comunicação, a questão se torna dramática. A imensa maioria dos instrutores de treinamento po. de vir em testemunho do elevado grau de rejeição que existe - observe-se, no entanto, que não pelo assunto, mas pela forma como \& ministrado e poucos efeitos de alteração - por parte dos grupos técnicos. Esses instru. cores com toda a certeza revelariam que é muito difícil a tarefa de reunir inteligentemente toda uma combinação de estimulos que promova interesse (que prenda a atenção logo no primeiro momento). Hå ataques, algumas vezes seguidos de evasão, quando não se dá a apreensão desse interesse. Pode haver tambêm a mera rolerância de esperar o curso chegar ao fim sem ter promovido o mi. nimo de interesse de envolvimento na iqual intensidade ao que ocorre nos assuntos técnicos (de interesse garantido).

Os treinandos desse íltimo caso, no momento da avaliaçäo declaram o velho diché: "É interessante isso";

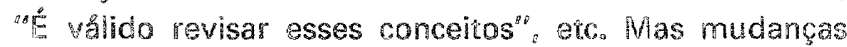
concretas năo ocorrem, e mesmo nenhum compromet. mento com elas se origina. É consensual que as comuni caçöes fazem parte das necessidades de qualquer grupo humano, e que é importante que sejam bem feitas. $\mathrm{PO}$. rém, o estudo sistemåtico, o desenvolvimento de uma metalinguagem como fator regulador e "gerador" dessa boa comunicaça ainda deixa a desejar, e não passa da condição de mais um "ponto ideal" que faria parte da sompetência para gerenciar.

A conclusảo, para o interesse deste trabaho de pesquisa $\hat{b}$ de que há necessidade primeiramente do "despertar" as pessoas lgerentes, fenicos ou butros! para o fato de que sảo produtores de linguagem. $15 s 0$ conseguido será garanuida a continuidade am oposiçäo ao desinterer se que motiva a evasäo. O convivio enure as instâncias de produzir linguagem a melhorar essa lingua. gem levarå a conhecimentos maiores do universo geren. cial nos múltiplos contextos particulares do pails.

\section{UMA FONTE TPGCA I INEXPLORADA DE DADOE}

Uma pesquisa foi raalizada utilizando um conjunto de seminários ministrados em cidades do norte do Para nă e sul de Säo Paulo e também Foz do lguaçu. Foram ursos apresentados na forma de módulos inseridos am programa de pơs-graduação em nivel de Especialização. A caracteristica principal desses programas é seu objetivo de promover formação especializada em Administração Geral e Estratégica, A clientela ê constituida de profissio. nais de empresas de diversos ramos, com predominância daqueles individuos que jả exersem cargo de gerência, ou 
alguma outra modalidade de chefia, e também aspirantes a cargos de chefia, que se acham em fase de pré-qualificação.

Os seminários foram preparados tendo em foco a questão de perfil (já mencionada). Por tratar-se de tema que normalmente não figuraria neste tipo de curso, pelo menos de forma pretendida, era de se supor que haveria necessidade de trabalhar o obstáculo (rejeição) que emergiria, e seria manifestado de diversas maneiras, indo desde apatia a formas explicitas de ataque. Um cuidado também foi tomado, o de selecionar toda exemplificação a ser utilizada, de dentro do universo verbal daquela clientela. Assim, procuraram-se artigos da revista Exame, textos extraídos das páginas de Economia e Administração de Negócios dos principais jornais, assuntos extraidos de livros de Administração, e também materiais originados das práticas cotidianas de comunicação na empresa.

O nome dado ao módulo foi Comportamento Organizacional - Comunicaça mas Empresas, e a ênfase não ficou concentrada unicamente na modalidade escrita. $O$ desafio era preparar um conteúdo que embora constituido de pontos básicos, seria apresentado de maneira estimulante. $O$ que se pretendia, além da pura transmissão da matéria, era fazer surgir uma manifestação de interesse. O objetivo foi conseguido, podendo-se indicar que houve pedidos para indicação de bibliografia para consulta posterior, acompanhados de expressåo feita verbalmente: "Eu não fazia idéia de que estudar linguagem fosse tão diferente; eu não estava habituado a isso - em nossa graduação nunca o tema foi tratado dessa maneira".

A seqüência de tópicos começa com um apanhado histórico a respeito das concepçôes de linguagem hoje existentes, culminando com a pergunta: "O que cabe a nós como produtores de linguagem nos dias que cor rem?"

Terminada essa etapa de conceituaçăb os participantes foram reunidos em grupos, com a tarefe de fes ponder: Cite cinco problemas encontrados na comonoca.

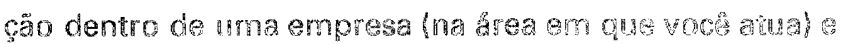

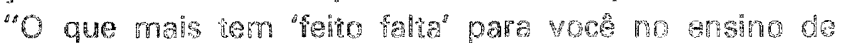
portuguas que voce teve ato agora?" lobsce o tricho do escolarizaçal. As respostas, nesta tarefa, toram recohth das por escrito. Tempo: 25 minutos.

Os principais pontos levantados foram:

Excesso de detalhes terniche a pormenores. Ha uma prolixidade generalizada no trato de questóes entre técnicos. A laicidade no país ẻ tratada com segregação. Não importa a experiência prática que se possua que de fato "autorize" um profissional a se pronunciar. Para poder fazer parte da "corporação" tem que estar autorizado por um curso de graduação e registro num conselho regional. Mas o que os participantes querem frisar é que falta às pessoas, quer na comunicação verbal, quer quando escrevem, objetividade.

Centralização de decisões. Aqui, o que se está apontando é a dificuldade gerencial de delegar tarefas e responsabilidades. Há, na realidade, um certo medo Semina Ci. Soc./Hum., v. 15, n. 3, p. 280-284 algumas vezes um acentuado medo - de delegar. Ao invés de estimular o subordinado a tomar iniciativa, aprender mais, a de fato crescer profissionalmente, o gerente prefere trazer para seu próprio cargo, todo tipo de decisão, vindo a sofrer um verdadeiro congestionamento de assuntos que acabam por ficar sem resolução, ou com solução incompleta, pois não hả meios de estar presente em tudo e controlar tudo, sớ da perspectiva do gerente. Mas há o medo de que, sabendo mais, o subordinado possa superá-lo e tomar seu lugar. A postura apregoada nos cursos de educação gerencial é a de que o gerente se interesse pelo sucesso de seu subordinado: se este tor nar-se sempre mais apto, jamais será ameaça: será garantia de sucesso da liderança gerencial.

Demora pelos caminhos formais. Há toda uma "parafernália" dentro das organizações, principalmente visando aos controles. "requisições para isso", "requisjções para aquilo", é a expressão coloquial utilizada por todos quantos presenciam o dia-a-dia da burocracia de produção. Os setores de controladoria financeira jamais abrem mäo dos fluxos de documentos que devem ser seguidos, a fim de satisfazer os inưmeros sistemas de con. trole de um processo contábil. E também, a "paranóia" com as auditorias; cada um tentando se "proteger" como pode das "anotaçóes" feitas por essas inspetorias. Em seu conjunto, todos esses procedimentos formam o que está sendo apontado aqui como caminhos formais que retardam as comunicaçōes. $\mathrm{Ha}$ uma corrente de adminis. tração ${ }_{s}$ de inspiração japonesa, que sustenta que se deve eliminar o quanto possivel a burocracia interna, princio palmente a de fábrica, mais diretamente ligada à produ. çăo. Mesa cheia seria sinônimo de ineficiência e perdas. a essência do sistema chamado Kanban, originado na fi. losofia de "produçăo só na hora necessária" (just-in-time). A prătica ocidental é a de recomendar sempre que se evitem ordens verbais: "Escreva - verba volann". Na era da informática e da difusäo do computador as de. moras causadas pelas necessidades de formalizacar do dis

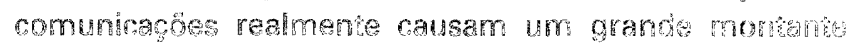
destrestracks.

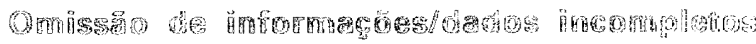

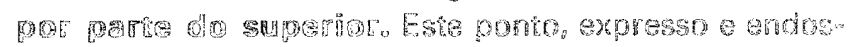

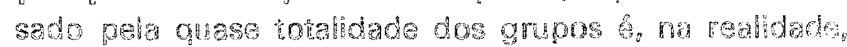
un dos mothos centrais a inspirar esto hvestigegă 0

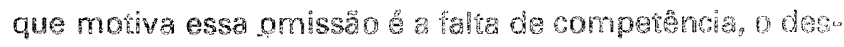

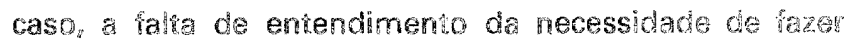
bem as comunicacóes? As causas se acham misturadas 6 torna-se dificil determină-las. Pode-se levantar tanto a hipótese de que essa omissão seja involuntăria como a de que seja propositada. De qualquer forma, o fato de esse problema ter sido mencionado quando se solicitou a um grupo de profissionais que falassem espontaneamente dos problemas que afetam suas organizações, atesta o grau em que não é compreendida a função gerencial de produzir linguagem. Pode-se mesmo dizer que, de qualquer forma, algum tipo de linguagem está sendo produzido - o da omissão - deliberada ou não, mas que nem sempre é a atitude que melhor se ajusta às conveniências do trabalho em equipe; do esforço coletivo 
em busca de melhores resultados, e maior grau de bemestar. Como emissor de instruções, o gerente deve prestar atenção a essa carência.

Diferenças de interpretação da mesma mensagem. Com isso os participantes desejam reafirmar a clåssica divergência de sentido nas mensagens. Abordar este ponto se torna algo de pleno sentido nesta altura do programa, uma vez que se torna possível lembrá-los da questão de "preenchimento", já abordada anteriormente. Há uma intensa participação quando se convida a esse tipo de correlação. Também é comentada a questão dos "esquemas" que possulmos e que são acionados pelo processo comunicativo. Os participantes, neste momento, fazem automaticamente a correlação com idéias apresentadas durante o módulo - Há esquemas que quando acionados em cada um de nós, são tão fortes, que subordinam qualquer outro em grau de importância. É um tema que promoveria amplas discussões.

Diferenças (educação e bagagem) de emissores/receptores. Num dado momento de suas vidas, as pessoas se descobrem fazendo parte de um grupo. As origens individuais são as mais variadas, e não poderia ser diferente. Numa cidade como São Paulo, altamente cosmopolita, o elemento originário da cidade convive ao lado do dominicano, do coreano, do nordestino, do italiano, e todo o amálgama cultural que também é típico do pais. Há um termo equivalente em inglês, para "bagagem", também de uso bastante comum: "background". Essas pessoas têm diferentes backgrounds e é de se imaginar que quando se encontram fazendo parte do mesmo grupo, haja colisões e consequências no processo comunicativo. Também, é necessário pensar numa questão não menos importante, que igualmente predispõe aquele processo à vulnerabilização: a questão do perfil, já tratada. Não se deve minimizar a tendência das pessoas a prezarem unicamente sua formação, e julgar que um zelo maior pela competência de interação - até

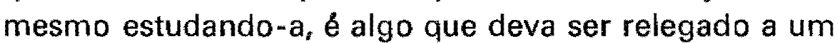
segundo plano.

\section{OUTROS PONTOS LEVANTADOS}

Informações ultrapassadas continuam em edital; atrasos na chegada de mensagens; informações verbais distorcidas; sonegação de informaçäo por parte de chefias (pode ser referenciado ao item omissão, já citado); deficit de informação para realizar o trabalho; falta de clareza nas comunicações; falta de objetividade.

As respostas à pergunta " $O$ que faz mais falta dentro do ensino de português recebido até agora" foram: professores competentes; noções de como interpretar textos; dificuldades com Análise Sintática; grafia das palavras; técnicas de Redação; Concordância: habilidade de comunicação oral; conjugações verbais.

Foram discutidas as implicações de cada um dos itens, lembrando o quanto a concepção de linguagem contida nas observações é a de produto e não de processo. Fica também evidente a crítica aos docentes como responsáveis pelo fracasso de aprendizado, ou mesmo pela frustração subseqüente de não ser possível dar conta do vasto campo de aprendizado que é o conjunto de uma língua. Ficou, de igual modo ressaltado que, o aprimoramento da competência com a lingua portuguesa, nesta altura da vida profissional de cada um, não significa mais uma mera reciclagem de conhecimentos. É necessário estudar as implicações mais amplas do processo de aquisição e manejo de linguagem - e isso só pode ser feito dentro do âmbito da profissão em que estão hoje inseridos.

Será impossivel para um profissional de gerência passar pelas funções que the são atribuidas como parte de sua tarefa, tais como planejar, organizar, liderar e controlar, sem que passe minimamente por alguma modalidade de fala e escrita. Sobretudo a segunda função, a de organizar as condições para possibilitar o trabalho é a que vai requerer a emissão de instruções. Essa é uma função que se iguala em importância à própria missão de lidar com gente.

Ao ser promovido para uma posição gerencial ou a qualquer nivel de supervisão ou coordenação, o detentor desse tipo de cargo precisa de imediato compreender que, a partir do momento em que o está assumindo, deixou de ser um executante direto; passou a ser alguếm que orienta a execução. É válido lembrar a dimensão de que ele não é mais quem faz o trabalho, mas é quem fazfazer o trabalho. Trata-se de uma mudança que deve afetar em profundidade sua maneira de ver e sentir tudo o quanto via e sentia antes em seu ambiente profissional. Não poderão mais ser-lhe estranhos os "componentes da bagagem" tais como cultura, valores, conhecimentos, crenças, idiossincrasias... das pessoas.

Escrever dentro da condiçâo prática das organizações significaria emitir uma $\mathrm{Cl}$ na qual estejam presentes as principais articulações de sentido. Significa também emitir correspondências externas que atinjam seus objetivos e não comprometam, com suas eventuais caracter'sticas, a boa imagem da organização. E se poderia seguir efetuando enumerações de assuntos específicos nos quais a questão central seria a mesma: habilidade. Vamos encontrar, do outro lado da linha, profissionais e instituiçōes reconhecendo carências e necessidades de supri-las. E se deseja velocidade. 
CONTANI, M.L.; FREGONEZI, D.E. Training on business communication: tips for content selection. Sem ina: Ci. Soc./Hum., Londrina, v. 15, n. 3, p. 280-284, Sept. 1994.

ABSTRACT: This text is a report on a series of experiments conducted with groups of managers enrolled in Postgraduate courses. It seeks to present the particular attitude such professionals have towards their shortcomings in language usage and communication - their peculiar views of such problems. The interpersonal relationship typical to working organizations is analysed and so are the reasons for failure of the continuous attempts on the part of communication skills training leaders. In its final part, this text provides topics for a thorough analysis meant to be helpful to the areas of human resources administration, training and development, faculty members and other professionals.

KEY-WORDS: Communication; training; languages.

\title{
REFERÊNCIAS BIBLIOGRÁFICAS
}

BLIKSTEIN, kzidoro. Técnicas de comunicaçăo escrità. São Paulo: Ática, 1989.
FIORiN, Jose Luiz. Linguageme ideologia. São Paulo: Ática, 1988.

\section{A VISÃO MODERNA DO PROCESSO EM CÂNDIDO DINAMARCO}

\author{
ARNALDO SAMPAIO DE MORAES GODOY ${ }^{1}$
}

GODOY, A.S. de M. A visåo moderna do processo em Cândido Dinamarco。 Samina: Cís Soc.dHumo, Londrina, V。 15 , n. 3, p. 284-286, set, 1994.

RESUMO: Neste ensaio apresenta-se a modernidade da posição do Professor Cándido Rangel Dinarnarco, que revoluciona os conceitos tradicionais de enfoque e de abordagem do Direito Processual, na tritha de uma busca do processo enquanto instrumento de realização de Justiça efetiva, como elemento componente dos escopos políticos do Estado. Para o Professor Dinamarco o processo precisa ser avaliado e estudado de seu ângulo externo, não se resumindo em estéreis discussốes acerca de questôes técnicas de ordem procedimental, mas sim dentro do resultado de um serviço público colocado a disposição do cida. dão.

PALAVRAS-CHAVE: Cândido Dinamarco, Análise Externa do Direito Processual, Efetividade da Justiça, Realizaçäo de Objetivos Polfiticos.

\section{1 - INTRODUÇĀO}

Este ensaio nasceu de um seminário apresentado no Curso de Mestrado em Direito da Universidade Estadual de Londrina, na disciplina de Teoria Geral do Processo, cadeira regida pela doutora Mariulza Franco. Foi produzido por reflexões em torno do capitulo Jurisdição e Poder, encontrado no livro A Instrumentalidade do Processo, de autoria do Professor CÂNDIDO RANGEL DINAMARCO (1993), capitulo contagiante, a enunciar novos tempos no estudo do Direito Processual.

\section{2 - A DESCOBERTA DE CÂNDIDO DINAMARCO}

Tem a sociedade a noção do jurista convencional: geralmente de terno, carregando uma pasta, dono de vocabulário burlesco, orador de plantão nas festas e encontros, a citar Ruy Barbosa, seu modelo mais acabado. De. fensor da legalidade, para ele a vida social radica num sólido ediffcio de proposições jurldicas.

No entanto, o arquétipo do leguleio, como forte no imaginário popular, vem sendo desmistificado pela novissima geração, plenamente identificada com axiologia

1 - Procurador da Fazenda Nacional, Docente de Direito Público na Universidade Estadual de Londrina. Mestrando em Direito Processual Civil. Londrina, Paraná, Brasil, Caixa Postal 6001, CEP 86051-970. 
mais real do universo juridico, a exemplo de DINAMARCO (1993).

Professor titular da Faculdade de Direito da Universidade de São Paulo, antigo Desembargador do Tribunal de Justiça daquele estado, do qual também foi Procurador de Justiça, Cândido Dinamarco, advogado militante, especialista em Direito Processual Civil, é autor de inúmeras obras, a exemplo de A Instrumentalidade do Processo, que o projeta na vanguarda da nova mentalidade jurldica que se constrói no pais.

Para ele, o processo há de ser integrado às institui: ções sociais, como matiz da realidade pela qual passamos, identificado na linguagem do homem comum, a realizar com eficiência valores efetivos, pelo que propõe seja a disciplina estudada pelo seu ângulo externo, a contrário do tradicional enfoque dado ao tema, preso a quezilias e pormenores de uma técnica, que tão somente tangenciam seus reais problemas, de efetividade da justiça.

\section{3 - UMA NOVA VISÃO DO PROCESSO}

O caricato jurista de formação latina tem o hábito de avaliar o processo a partir do instituto da Ação (em sua autonomia ou dependência para com o Direito chamado material ou substancial), ranço de uma época afetada por concepções jurídicas privatísticas. Assim, para o jurista educado nos conceitos tradicionais, o processo é ciência, devido, tão sơ, a problemas que the são próprios, a que the emprestam um bem construido disfarce de autonomia, de resto irrelevante para o real interessado, o cidadão que dele precisa para a composição de seus conflitos. No entender de Dinamarco (1993) tal postura é falaciosa, pois, a par da matéria processual ser pública (inserida no sistema politico, a realizar seus objetivos), tem ala uma teoria geral, informada por princípios que não the são únicos, informando tamberm o processo penal, onde a idéia de proteção ao individuo tem natureza dim versa, e distinta.

O processo há de ser avaliado de seu ângulo externo. Afinal, se aproxima da política, como elemento mesmo de poder, este tomado no sentido da escolha de ca. minho. Sua teoria geral demanda uma abordagem do poder, e seu exerclcio, inserindo a Ação como soma de poderes, co que distante do tradicional conceito que a caracteriza na iniciativa processual e na resposta à demanda. Entäo, conclui Dinamarco (1993), a Ação não pode estar no centro do direito processual, porque demais marcada pelo individualismo e pela inegåvel restrição ao direito civil. $\mathrm{Na}$ consecuçăo de seus desideratos, deve se livrar de dogmas, na continua busca de uma isonomia desejável entre as partes, na trilha de antigo estudo de GRINOVER (1973), para quem "o direito de açăo e de defesa liga-se teleologicamente ao principio de isonomia. A igualdade perante a lei \& premissa para a afirmaçäo da igualdade perante o juiz. Indissoluvelmente ligada à de-

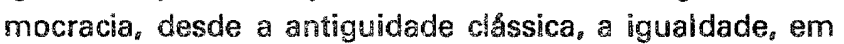
sentido moderno, tem ralzes incontestavelmente francesas".

Semina Ci. Soc. $/ H_{u m}, v_{0} 15, n_{0}$ 3, p. 284-286
DINAMARCO (1993) propõe o encontro do processualista com a realidade. Visto do ângulo externo, exige o processo um estudioso afinado com a Ciência Polftica, embora admoeste também, o que fático, que sociólogos e politicólogos não se interessam pelo processo jurisdicional. Com efeito, urge a criação de um posicionamento realista, a buscar a efetividade da justiça, a começar por um novo perfil da figura do magistrado. A sociedade também desconfia dos julzes, adverte AYDOS (1992). Importante se verifique que é a Magistratura no pals, a constituição de seu perfil, as conseqüências de seu recrutamento e o seu papel de prestígio na sociedade brasileira, como indaga VIEIRA (1992). Do que, além de uma produção acadêmica orientada para a solução desses problemas, não se pode perder de mira que a "função judicial não pode ser convenientemente avaliada sem relacioná-la com o sistema de direito em que se insere", na não menos judiciosa observação do Professor CARRION (1992)。

É o Estado que decide. Só ele. Sua voz, enquanto elemento de uma superestrutura multifacetária, consubstanciada na sentença, é mera positivação do poder. A jurisdição, nesse diapasão, é instrumento do mando, dentro do conceito de poder como capacidade de decidir imperativamente e impor decisões, ou a capacidade de "mandar e de ser obedecido", na referência que DINAMARCO (1993) fez a Vamireh Chacon e a Weber. Afinal, a sentença e sua qualidade de coisa julgada, como resultado da relação processual, é obrigatória para os sujeitos desta. Imunizando as relações de disputa, a autoridade de coisa julgada constitui afirmação mesma do poder, por paradoxal que possa parecer.

Assim, a jurisdição é uma das funçōes (serviços) dn Estado, no que o Professor Dinamarco encampa a jurisdição voluntária, como jurisdição efetiva, pois, inegavelmente, ato de poder. Nesse sentido, as construções chamadas de jurisprudenciais, a influenciar a atividade judicante revestem-se da aura da magia, dentro do velho principio de que a ${ }^{s t}$ jurisprudência é mais que um consetho e menos do que uma ordem".

Por isso, o estudo do processo a partir de seu ângulo interno (Ação) perde terreno para o estudo do processo a partir de seu ângulo externo (Jurisdição e realiza. ção de um serviço públicol, como instrumento a reconstruir a confiança na função jurisdicional do Estado.

A descrença para com a atividade judicante começa com a morosidade da justiça, no entender de TUCCl (1993). Transita para o formalismo (que radica em concepçōes privatísticas de processo e de Açäo) e redunda no caos. É o retorno à passagem da árvorè e da videira curiosa no direito romano.

Mas, felizmente, reações jå se desenham. A comecar pela obra de DINAMARCO (1993), a advertir que o estudo do processo carece de novos rumos e que precisa ser avaliado por seu ângulo exógeno, reduzido à finalidade da jurisdição, como fio a ligar o procedimento judicial às instituiçöes politicas. Criaçäo de juizados de pequenas causas, posturas que revelam a independência tão sonhada do judiciário (como no exemplo de Dinamarco que 
aponta o destemor de alguns Julzes Federais em liberação de cruzados e ações de natureza previdenciárial e uma produção acadêmica cada vez mais caudalosa, e cada vez menos rançosamente dogmática.

\section{4 - CONCLUSĀO}

Chegará o dia em que a caricatura do jurista será imagem de livro de História, de triste lembrança. Que a justiça será mais eficiente do que hoje e que, certamente, lembrar-se-á de DINAMARCO (1993) como um inovador, cuja liberdade e coragem contribuiram para ajustar a Ciência Processual ao ponto do qual jamais poderia ter se afastado: a realização da justiça.

GODOY, A.S. de M. The process modern point of view by Cândido Dinamarco. Semina: Ci. Soc./Hum., Londrina, v. 15, n. 3, p. 284-286, Sept. 1994.

ABSTRACT: On this essay it is shown Professor Candido Rangel Dinamarco's modern points of view for he builds up a revolution on the approach and emphasis of Procedure Laws. In search of the process as an instrument of perception of performed justice, as an element existing on State political goals. For him the process needs to be studied and evaluated from an outer exam and not based upon useless arguments of procedure techniques. In short, what is done for the citizen from public service is what really matters.

KEY-WORDS: Candido Dinamarco, Outer Exam of Procedure Laws, Process as Instrument of Perception of Performed Justice, Political Goals.

\section{REFERÊINCIAS BIBLIOGRÁFICAS}

AYDOS, Marco Aurélio Dutra. O Juiz-cidadão. In: AYDOS Marco Aurélio Dutra et al. Direito Atternativo. São Paulo: Acadêmica, 1992. p. 127. v. 1.

CARRION, Eduardo Kroeff Machado. O Poder Judiciário, o juiz e a lei. Revista de Direito Alternativo, n. 1, p. 67, 1992.

DIN AMARCO, Cândido Rangel. A instrumentalidade do Processo. São Paulo: Malheiros Edìtor, 1993. p. 77.

GRINover, Ada Pellegrini. Os Princtpios Constitucionais eo Codigo de Processo Civil. São Paulo: Josê Bushatsky, 1973. p. 25.
TUCCI, Rogério Lauria; TUCCl, Josê Rogério da Cruz e. Devido processo legale tutela jurisdicional. São Paulo: Revista dos Tribunais, 1993. p. 101.

VIEIRA, José Ribas. O Judiciário e a democratização adiada: alternativas. In: VIEIRA, Josê R ibas et al. Liçöes de Direito Alternativo: São Paulo: Acadêmíca, 1992. p. 117. 